\title{
Development of an Australian Standard for Wheelchair Occupant Restraint Assemblies for Motor Vehicles
}

\author{
W. E. FISHER, Ph.D.; B. R. SEEGER, Ph.D.; N. L. SVENSSON, Ph.D. \\ Regency Park Centre for Young Disabled, Kilkenny, South Australia 5009, Australia; and University of New South \\ Wales, Kensington, N.S.W. 2033, Australia
}

\begin{abstract}
An Australian Standard for Wheelchair Occupant Restraint Assemblies for Motor Vehicles has been produced. Titled Australian standard 2942-1987, Wheelchair Occupant Restraint Assemblies for Use in Motor Vehicles, it establishes design and performance requirements for these restraints, and includes details of dynamic testing procedures. Under the Standard, a lap belt is the basic occupant restraint required with the wheelchair restrained independently of the occupant. The Standard, instead of specifying a "standard" design for wheelchair occupant restraint assemblies, is intended to ensure effective crash protection for wheelchair occupants with a minimum of restriction on the design of restraints. It requires that instructions for installation and use of restraints be provided. Also included in the Standard is an advisory section providing general information for restraint users such as the types of wheelchairs best suited for use in vehicles. This appears to be the first national Standard for wheelchair occupant restraint assemblies for motor vehicles, and may well form the basis of similar standards elsewhere.

DOI $10.1682 /$ JRRD.1987.07.0023
\end{abstract}

\section{INTRODUCTION}

Many wheelchair users are able to transfer themselves from the chair and use standard passenger seats in motor vehicles. People who are unable to transfer, or who require special seating, may need to travel seated in their wheelchairs. The need for crashworthy wheelchair occupant restraints has been demonstrated $(6,9,11,13)$, but there are few official documents covering their design and application.
The United Kingdom Department of Transport Code of Practice and Special Provisions for the Carriage of Wheelchairs on Public Service Vehicles (2) covers, in general terms, design and performance requirements for wheelchair occupant restraints. The code specifies a static test for assessing wheelchair performance that is inexpensive and simple, but does not simulate dynamic events. The static test employs a frame on castors to apply test loads to the restraints, but no body form or dummy is used, thus the loads that may be applied independently by a wheelchair and its occupant cannot be simulated (5).

Motor Vehicles for the Transportation of Physically Disabled Persons (4), the Canadian National Standard, deals mostly with vehicle requirements as its name implies, and refers to Canadian seatbelt standards for the design and performance of occupant restraints. There are no specific design requirements for wheelchair restraints.

The State of California Requirements for Adaptive Equipment Purchased for Handicapped Drivers (7) provides general design and installation requirements for wheelchair occupant restraints and specifies the deceleration rate and velocity change of a dynamic test, but gives no details of a test procedure.

Following the development of a crashworthy wheelchair occupant restraint system at the Regency Park Centre for Young Disabled (12), which is now manufactured by Safe-n-Sound Pty. Ltd. (229 Great North Road, Fivedock, New South Wales 2046, Australia), we became acutely aware of the need 
Journal of Rehabilitation Research and Development Vol. 24 No. 3 Summer 1987

for a standard, so that providers of transport for people in wheelchairs could determine if their restraint systems were crashworthy.

In response to this need, the Standards Association of Australia established a committee to work on a Standard, with members from government regulatory bodies, restraint manufacturers, universities, and user organizations. The work was carried out in parallel with a project to develop a code of practice for wheelchair occupant restraints, funded by the South Australian Department of Transport and managed by the Rehabilitation Engineering Department, Regency Park Centre, South Australia.

\section{SPECIAL PROBLEMS WITH WHEELCHAIR OCCUPANT RESTRAINTS}

Protection against vehicle impact for motor car passengers is assured by attention to a host of details; seat belts, belt anchorages, seats, padding, and survival space are all subject to detailed requirements. These factors are also relevant to restraints for wheelchair occupants, but the use of nonstandard wheelchair seating certainly creates special difficulties.

\section{Design of Wheelchairs}

Some types of wheelchairs are not suitable for use as vehicle seats because of unsound structures or unsuitable design. However, studies elsewhere $(3,8)$ and our own dynamic tests $(10,12)$ indicate that many common types of wheelchairs can, if appropriately restrained, withstand simulated vehicle impacts without fracture or severe collapse of the frame. It may seem that the solution to this problem lies simply in standardizing the design of wheelchairs but, in the authors' opinion, this is not a feasible option at present. Many existing wheelchairs will be in use for years to come, and the process of devising and implementing effective standards for the crashworthiness of wheelchairs will be lengthy, if it happens at all. Standards for wheelchair occupant restraints are needed now, and the implementation of standards should not be delayed because wheelchairs are not ideal.

\section{Anchorage Points in Vehicles}

Few vehicles carry wheelchairs, and it is unreasonable to expect that vehicles will be manufactured with anchorage points for wheelchair occupant restraints. Furthermore, the diversity of existing restraint designs and the likelihood that new designs will appear renders a standard type of anchorage impractical. In general, vehicles will need to be reinforced at anchorages for wheelchair occupant restraints.

\section{Determining Appropriate Dynamic Performance Criteria}

Dynamic performance criteria for passenger car seat belts are not appropriate for wheelchair occupant restraints, for the following reasons:

1.) Typically, the seating position in a wheelchair is more upright than in a passenger car; the car's backrest is more reclined and the passenger's knees are more extended. Dynamic tests for passengercar seat belts are normally carried out with the feet of the test dummy resting on an angled part of the floor of the test rig, but this is not appropriate in the wheelchair seating position.

Our dynamic tests revealed that when using a lap belt to restrain the dummy, more severe belt loadings were experienced with wheelchair seating geometry than with standard passenger-car seating geometry. Consequently, lap belts that pass the standard dynamic test failed in tests where wheelchair seating geometry was substituted (Appendix A). Providing special seatbelt webbing and latching hardware for wheelchair occupants is not feasible; thus it is appropriate to reduce the severity of the dynamic tests used.

2.) Small production volumes, complexity in design, and need for reinforcing vehicles will make wheelchair occupant restraints expensive to implement compared with standard passenger car restraints. Acceptance of wheelchair restraints will depend on costs, and it is important to encourage the use of restraints by setting standards that can be achieved at reasonable cost. If the use of wheelchair occupant restraints becomes mandatory by law, high costs of implementation, due to overambitious standards, would prevent vehicle use by many wheelchair occupants.

Dynamic test conditions in the Standard represent achievable levels of protection in front, rear, and side impacts. They are intended to offer a reasonable level of protection, bearing in mind the typically larger mass of vehicles that carry passengers in wheelchairs. 


\section{STRUCTURE OF STANDARD}

The Standard is intended to establish basic design and performance requirements for wheelchair occupant restraint assemblies, at the same time providing for a wide range of restraint designs, including particularly those with extensive occupant protection and convenient operating features. The Standard applies to wheelchair passengers in motor vehicles and not to wheelchair occupants who are driving a vehicle. The restraint assemblies covered by the Standard are intended for use by adults or children, and for installation in all types of motor vehicles that are suitable for wheelchair transport. One level of dynamic testing is provided for all designs.

\section{Categories of Wheelchair Occupant Restraints}

Three categories of wheelchair occupant restraint assemblies were defined:

Type A: Restraints intended for use with wheelchairs that have not been specially designed or modified for use with the restraints; for example, Q'Straint (Canada).

Type B: Restraints designed with fittings to be bolted to the wheelchair frame; for example, Safe$\mathrm{n}$-Sound (Australia).

Type C: Wheelchairs manufactured with integral restraint hardware; for example, Carchair (United Kingdom).

\section{Design and Construction Requirements}

Requirements in design and construction cover such matters as wheelchair orientation in the vehicle, safety and convenience in normal use of restraints, means of fastening restraints to wheelchairs, types of occupant restraints and material used, anchor point positions for occupant restraints, operating characteristics of release mechanisms, provision of adjustments, and quality of manufacture. The minimum requirement for occupant restraint is a pelvic restraint such as a lap belt. Upper torso restraints are not mandatory, but the Standard contains requirements applicable to restraint assemblies with harness belts, lap-sash belts, and head restraints. The required survival space is reduced if an upper torso restraint is added to a basic lap belt system.

\section{Instructions}

Under the Standard a manufacturer of restraints is required to provide comprehensive instructions for installation and use. The instructions for installation must show the arrangement of single- or multiple-restraint installations to ensure adequate space around each wheelchair. The space required is determined by formulae that utilize measured excursions of the test seat and dummy during dynamic tests (Figure 1). The magnitudes and directions of anchor forces measured during dynamic testing must be given in the installation instructions to enable the vehicle reinforcements to be properly determined.

The instructions for use must describe the types of wheelchairs suitable for use with the restraints and describe the correct use of the restraints. Type $A$ restraints must be supplied with a durable instruction label suitable for attachment to the inside of the transport vehicle.

\section{Performance Requirements}

The Standard requires wheelchair occupant restraint assemblies to undergo dynamic tests simulating front, side, and rear impacts (Table 1). Horizontal excursions measured at the dummy's hip and shoulder during dynamic testing must be recorded. Restraint assemblies are required to retain the dummy in a test seat and retain the test seat on the test rig in an upright position, facing within 20 degrees of the orientation specified for a dynamic test. Loadbearing restraint components must not fracture or separate under testing, and release mechanisms must be operable by hand after testing.

\section{Test Seat}

Wheelchairs subject to dynamic testing are almost invariably damaged by deformation of the frame, stretching or tearing of the upholstery, and sometimes by fractures of the frame. Normal wheelchairs deform in dynamic tests, absorbing impact energy and reducing peak loads in restraint components. For these reasons, and because wheelchairs of different styles will not give consistent results under test, it is not practical to use normal wheelchairs for routine testing of wheelchair occupant restraints.

Our obvious solution is to use a damage-resistant test seat to represent the wheelchair. Figure 2 shows the dimensions of the test seat, defined in the Standard, to simulate a typical 55-kg battery-powered indoor-outdoor wheelchair in use in Australia. 


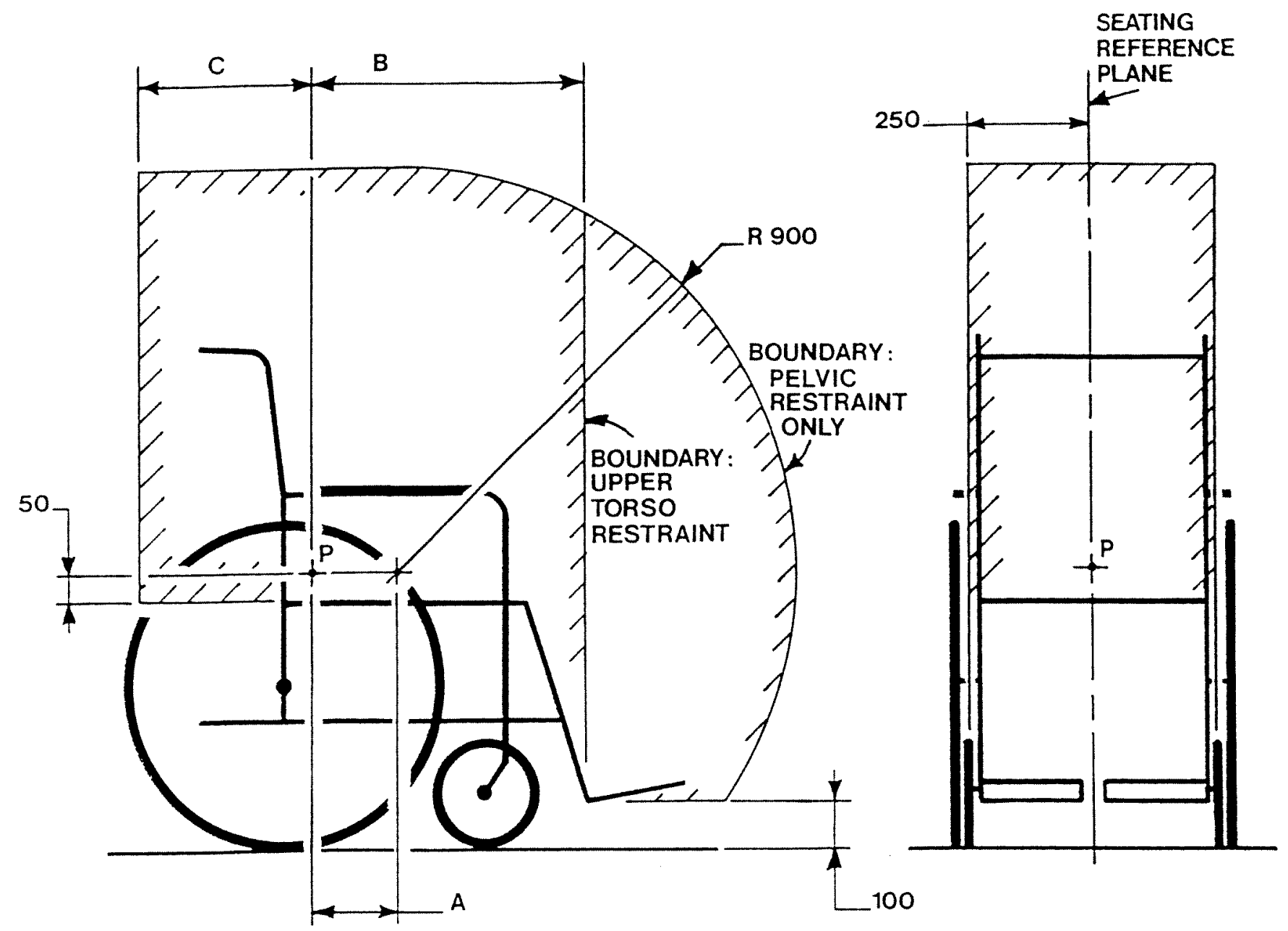

Figure 1.

Requirement for clear space around a wheelchair position. Dimensions are in millimeters. The dimensions A, B, and C are determined by specified dynamic tests. Point $\mathrm{P}$ is defined in the Standard.

Table 1

Dynamic Test Conditions under the Standard

\begin{tabular}{|c|c|c|c|}
\hline \multirow[b]{2}{*}{$\begin{array}{c}\text { Test } \\
\text { Condition }\end{array}$} & \multicolumn{3}{|c|}{ DIRECTION OF IMPACT } \\
\hline & Front & Side & Rear \\
\hline Velocity Change & $\begin{array}{l}9.7 \pm 0.3 \mathrm{~m} / \mathrm{s} \\
(35 \mathrm{~km} / \mathrm{h})\end{array}$ & $\begin{array}{l}8.9 \pm 0.3 \mathrm{~m} / \mathrm{s} \\
(32 \mathrm{~km} / \mathrm{h})\end{array}$ & $\begin{array}{l}4.5 \pm 0.3 \mathrm{~m} / \mathrm{s} \\
(16 \mathrm{~km} / \mathrm{h})\end{array}$ \\
\hline $\begin{array}{l}\text { Specified Range of } \\
\text { Deceleration }\end{array}$ & $\begin{array}{l}196 \text { to } 234 \mathrm{~m} / \mathrm{s}^{2} \\
(20 \text { to } 24 \mathrm{~g})\end{array}$ & $\begin{array}{l}137 \text { to } 196 \mathrm{~m} / \mathrm{s}^{2} \\
(14 \text { to } 20 \mathrm{~g})\end{array}$ & $\begin{array}{l}78 \text { to } 147 \mathrm{~m} / \mathrm{s}^{2} \\
(8 \text { to } 15 \mathrm{~g})\end{array}$ \\
\hline $\begin{array}{l}\text { Duration of } \\
\text { Deceleration within } \\
\text { Specified Range }\end{array}$ & $\begin{array}{l}\text { Not less than } \\
15 \mathrm{~ms}\end{array}$ & $\begin{array}{l}\text { Not less than } \\
15 \mathrm{~ms}\end{array}$ & $\begin{array}{l}\text { Not less than } \\
10 \mathrm{~ms}\end{array}$ \\
\hline $\begin{array}{l}\text { Duration for which } \\
\text { Deceleration exceeds } 20 \mathrm{~m} / \mathrm{s}^{2}\end{array}$ & $\begin{array}{l}\text { Not more than } \\
100 \mathrm{~ms}\end{array}$ & $\begin{array}{l}\text { Not more than } \\
\quad 90 \mathrm{~ms}\end{array}$ & $\begin{array}{l}\text { Not more than } \\
70 \mathrm{~ms}\end{array}$ \\
\hline
\end{tabular}




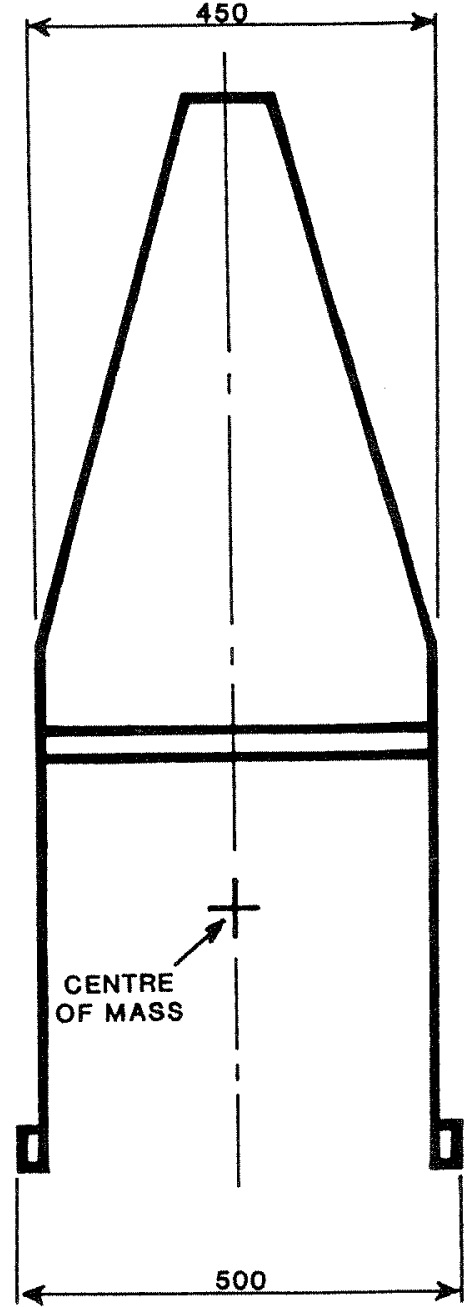

FRONT

ELEVATION

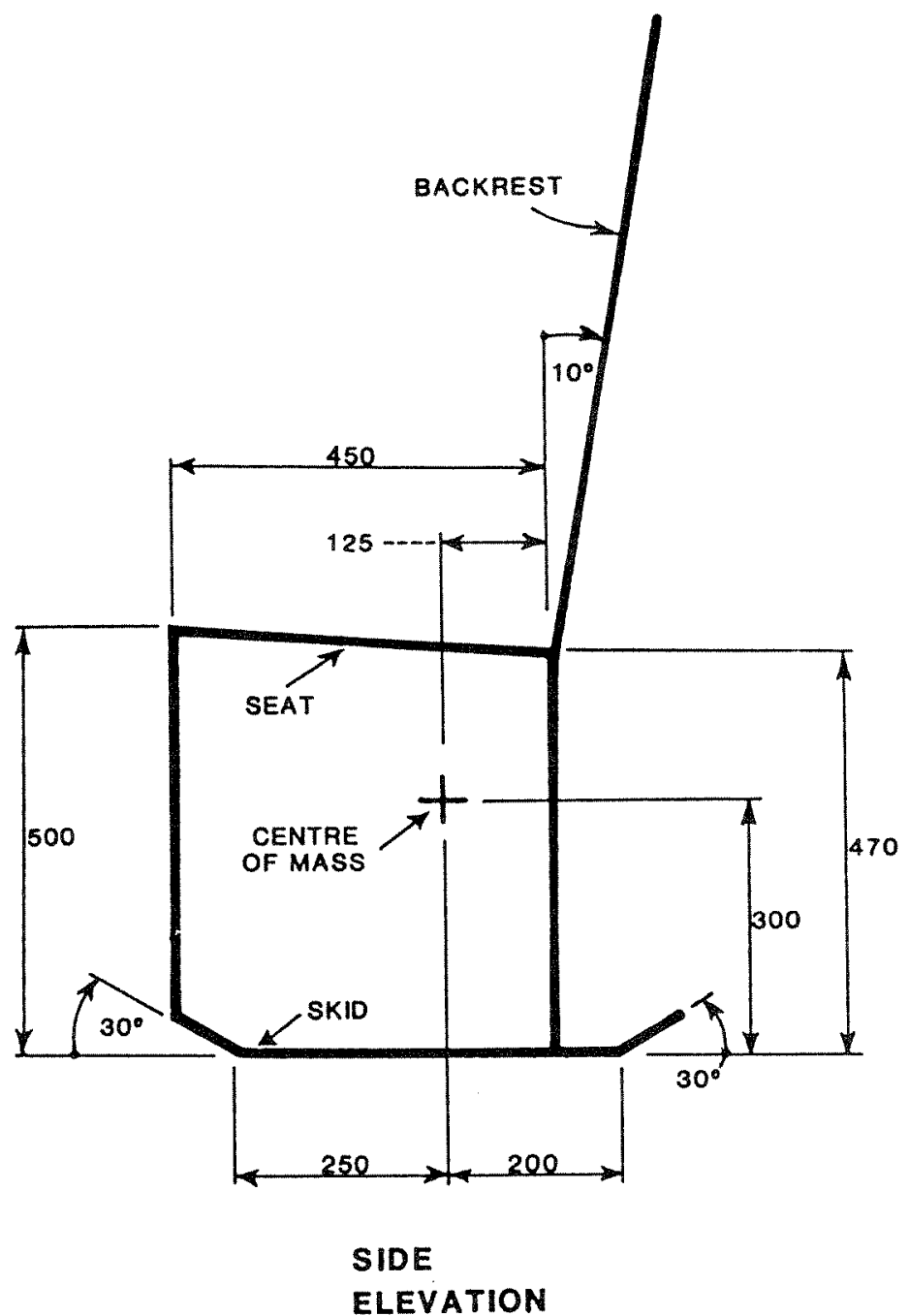

Figure 2.

Test seat dimensions (in millimeters) specified in the Standard.

In order to obtain fair representation of the restraint loads produced by a $55 \mathrm{~kg}$ wheelchair, the mass of the test seat should be less than $55 \mathrm{~kg}$. A series of comparison tests were run to determine a suitable mass for the test seat (Appendix B). It was found that a test seat of $36 \mathrm{~kg}$ generated slightly larger loads under test conditions than a representative wheelchair of $55 \mathrm{~kg}$. The test seat is much more rigid than a wheelchair and does not deform plastically during testing. The seat's high back is required to prevent damage to the dummy's neck by whiplash. Systems with restraint hardware incorporated into the wheelchair frame (Type C) are tested with the wheelchair instead of the test seat.

\section{Advisory Parts of the Standard}

The Standard contains advisory appendices to disseminate useful information beyond the scope of the mandatory sections. These appendices give general advice about vehicles suitable for transporting occupied wheelchairs and the reinforcement of vehicles for wheelchair restraints, and cover the selection of wheelchairs for use in vehicles and safety aspects of wheelchair accessories and fittings. Further general advice is available in the form of an illustrated, easy-to-read brochure entitled "Wheelson-Wheels," produced by the Rehabilitation Engineering Department, Regency Park Centre for Young Disabled. 


\section{SUMMARY}

The effective application of wheelchair restraints depends on good design and manufacture, and correct installation and use. Australian Standard 29421987, Wheelchair Occupant Restraint Assemblies for Use in Motor Vehicles sets out manufacturing and performance requirements, instructions for installation and use, and design of a test seat. It also offers advice about vehicle selection and reinforcement, restraint installation, and the choice of wheelchairs suitable for use in vehicles. To facilitate effective communications between manufacturers, installers, and users of wheelchair occupant restraints, the Standard establishes a system of information flow, illustrated in Figure 3. For example, the standard requires a manufacturer to provide instructions for installing a restraint product. This information is useful not only to installers but also to transport providers who need to know the space required for an installation.

The Standard sets out basic design and performance requirements considered to be appropriate for current conditions in Australia, and provides design guidelines for manufacturers who wish to produce restraints giving greater protection than the minimum. In preparing the Standard, we emphasized ensuring effective crash protection for wheelchair occupants with a minimum of restriction for restraint designers.

Copies of Australian Standard 2942-1987: Wheelchair Occupant Restraint Assemblies for Use in Motor Vehicles, may be obtained from: The Standards Association of Australia, P.O. Box 458, North Sydney, N.S.W. 2060, Australia; or, The American National Standards Institute, 1430 Broadway, New York, NY 10018 (212) 354-3300.

\section{Acknowledgements}

Funding for work contributing to the development of a standard for wheelchair restraints was provided by the Transport Planning Division, Department of Transport, South Australia. Rainsfords Metal Products Pty. Ltd. of Lonsdale, South Australia, made available their dynamic test rig for trials required during preparation of the Standard. The Design Arts Board of the Australia Council funded preparation of the brochure and video, "Wheels on Wheels."

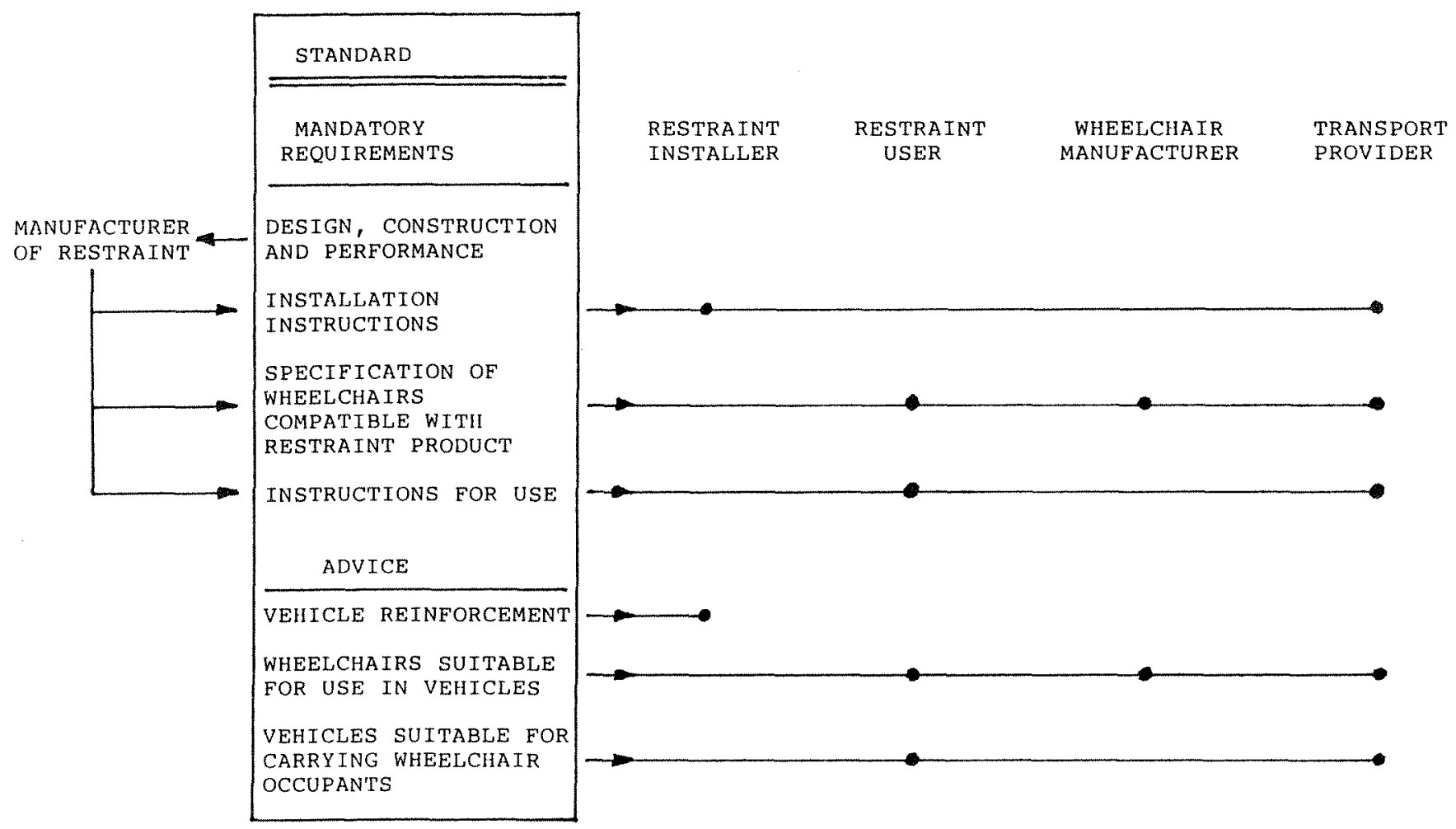

Figure 3.

Information flow established by the Standard. 


\section{APPENDIX A \\ VARIATION OF LAP BELT LOADS WITH WHEELCHAIR SEATING GEOMETRY}

Certification tests for lap belts in Australia require dynamic tests with a seating geometry defined in ADR 4 (1) and shown in Figure 4. The test dummy is supported in a reclined position with the feet supported on an angled surface. With wheelchair seating geometry, the dummy is supported in an upright position on the test seat (see Figure 2) with the lower legs and feet hanging free. Dynamic impact tests were carried out to determine the effect of the different seating geometries on lap belt loads.

\section{Test Conditions and Equipment}

The test setup was as follows:

1.) Orientation: forward facing, front impact

2.) Test Dummy: TNO 10, $75 \mathrm{~kg}$

3.) Seats: ADR 4 seat; Standard test seat

4.) Restraints: seats bolted to test sled; dummy restrained by lap belt.

Typical dynamic test conditions were:

1.) Velocity change: $13.3 \mathrm{~m} / \mathrm{s}(48 \mathrm{~km} / \mathrm{h})$

2.) Peak deceleration: $216 \mathrm{~m} / \mathrm{s}^{2}(22 \mathrm{~g})$

3.) Duration of deceleration exceeding $177 \mathrm{~m} /$ $\mathrm{s}^{2}(18 \mathrm{~g}): 45 \mathrm{~ms}$.
NOTE: All tests were conducted with the same rig settings and sled mass.

\section{Test Program}

Five trials were conducted with belt load transducers fitted to both ends of the lap belt. The results of one trial were discarded because the lap belt tore on a sharp projection on the test seat.

\section{Results}

Contrary to expectations, peak lap belt loads with test seat geometry were not significantly greater than those with the ADR 4 seat geometry (Table 2). There was, however, a marked difference in the duration of belt loading; a typical comparison of loading traces is shown in Figure 5. This difference appears to be related to the support provided by the footrest in the ADR 4 seat and the dynamic behavior of the dummy during impact. On impact, the dummy moved forward against the lap belt, the hip flexed, and the torso rotated forward, ultimately striking the upper leg. With the ADR 4 seat the impact of the torso on the upper leg was arrested by the lower leg which was well supported. With the test seat, which has no support for the lower leg, when the dummy's torso rotated down to the upper leg, the

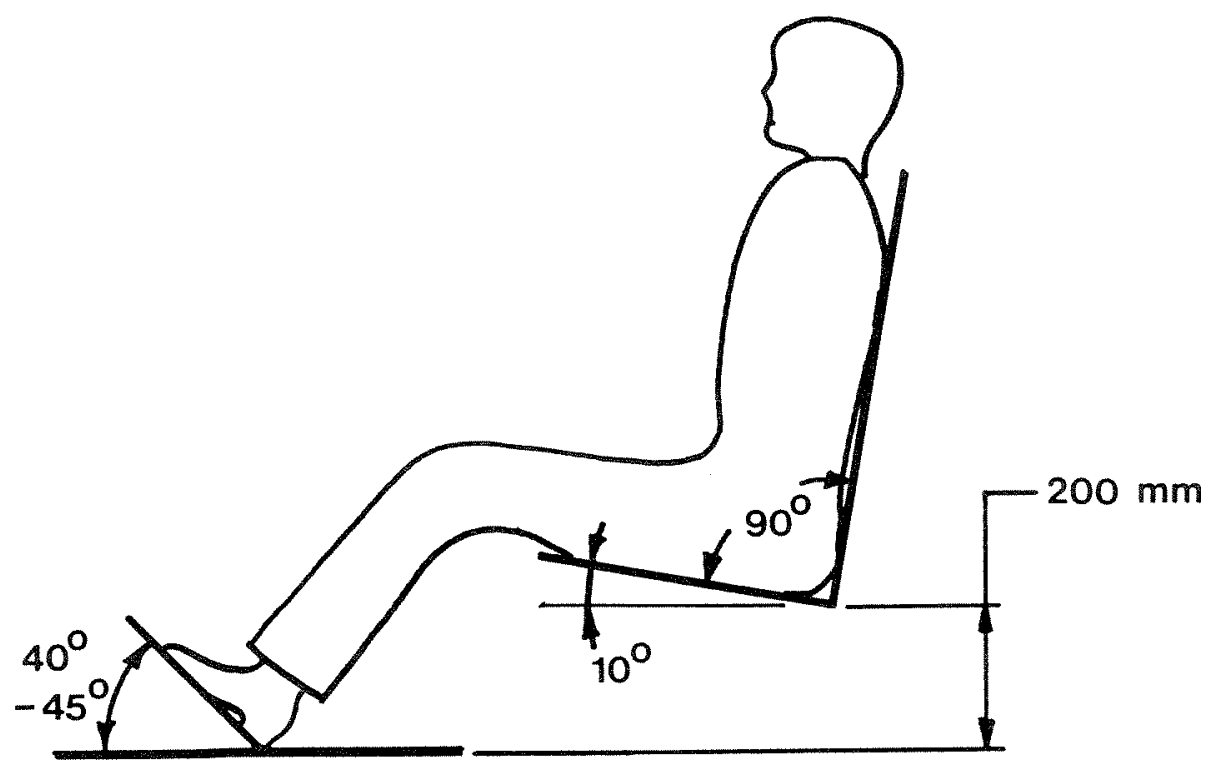

Figure 4.

Test seat geometry specified for dynamic testing by Australian Design Rule 4D (ADR 4D). 
Journal of Rehabilitation Research and Development Vol. 24 No. 3 Summer 1987

\section{Table 2}

Lap belt loading measured during dynamic testing with two seat geometries. The restraining forces shown are the sum of the lap belt tension in the two sides of the belt.

\begin{tabular}{|c|l|c|}
\hline Trial & $\begin{array}{l}\text { Seating } \\
\text { Geometry }\end{array}$ & $\begin{array}{c}\text { Peak Restraining } \\
\text { Forge }(\mathbf{k N})\end{array}$ \\
\hline 1 & ADR 4 & 19.8 \\
2 & ADR 4 & 18.9 \\
3 & Test Seat & 20.7 \\
4 & Test Seat & 20.2 \\
\hline
\end{tabular}

flexed dummy rotated about the forward edge of the test seat until ultimately restrained by the lap belt, extending the time during which high loads were applied to the belt.

\section{Conclusions}

The geometry of seating in the Standard test seat leads to a longer duration of lap belt loading than those experienced with the ADR 4 seat. This explains failures of lap belts that were observed in dynamic tests according to ADR 4, but using the Standard test seat.

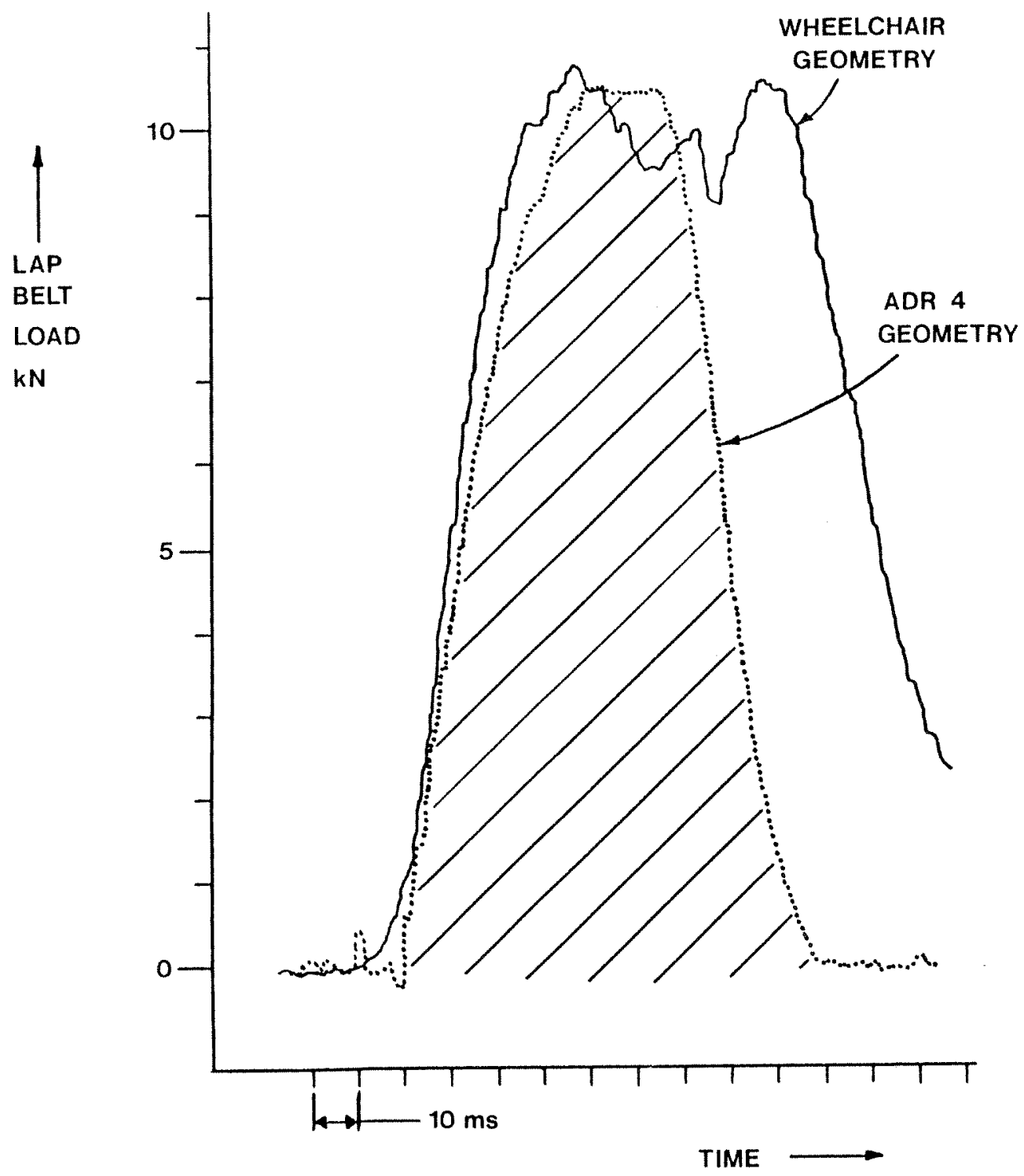

Figure 5.

Comparison of lap belt loading traces during dynamic testing with two seating geometries: wheelchair seating geometry and passenger-car seating geometry. 


\section{APPENDIX B DETERMINATION OF TEST SEAT MASS}

Dynamic impact trials were carried out to determine the appropriate mass for the test seat specified in the Standard, and intended to simulate a typical battery-powered wheelchair of $55 \mathrm{~kg}$. Preliminary trials indicated that a test seat mass of $36 \mathrm{~kg}$ would be suitable. Results of final trials to validate this mass are presented here.

\section{Test Conditions and Equipment}

The test setup was as follows:

1.) Orientation: forward facing, front impact.

2.) Test Dummy: TNO 10, $75 \mathrm{~kg}$.

3.) Seats: (A) Standard test seat, $36 \mathrm{~kg}$ (Figure 1); and (B) Zimmer GB battery-powered wheelchair, $55 \mathrm{~kg}$.
4.) Calibration of dynamic tests: Velocity change on impact $=1.03 \mathrm{~m} / \mathrm{s}(37 \mathrm{~km} / \mathrm{h})$; peak deceleration $=216 \mathrm{~m} / \mathrm{s}^{2}(22 \mathrm{~g})$; and time during which deceleration exceeded $177 \mathrm{~m} / \mathrm{s}^{2}(18 \mathrm{~g})=27 \mathrm{~ms}$.

5.) Restraints: Restraints manufactured by Safe$\mathrm{n}$-Sound Pty. Ltd. were used to restrain the wheelchair and TNO 10 dummy, but the rear straps were modified to permit the fitting of a belt load transducer. The Safen-Sound restraints (Figure 6) include two webbing straps that fasten around the front uprights of a wheelchair, a lap belt to restrain the occupant, and two straps at the back. The rear restraint straps and lap belt are anchored to a bracket fastened to the rear uprights of the wheelchair.

For test purposes the two rear restraints were replaced with two special belts, each being a length

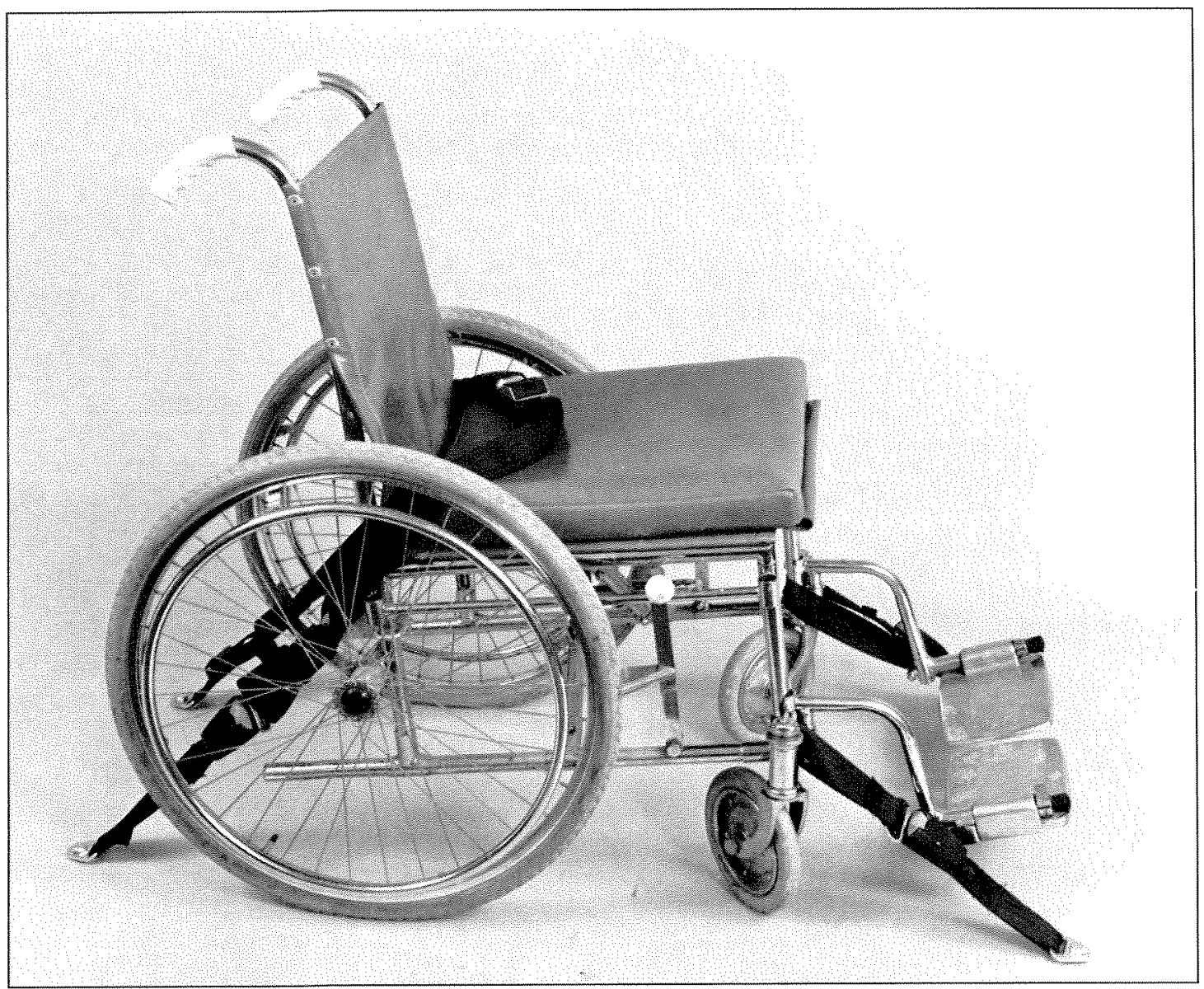

Figure 6a.

The Safe-n-Sound wheelchair occupant restraint system. 
of webbing looped through the eye of the wheelchair bracket with the free ends anchored to the test seat. One of the rear restraints carried a belt load transducer. To avoid overshoot of the recording instrument, the transducer was mounted on a single strand of the looped webbing of the rear restraint, so the transducer was exposed to only half of the total restraint loading.

\section{Test Program}

Four trials were conducted, two with the Zimmer GB wheelchair and two with the test seat. Ballast was added to the test frame in order to keep the total rig mass constant with the two different seats.
Table 3

Peak loads observed in rear restraints during dynamic testing using a typical powered wheelchair and the Standard test seat

\begin{tabular}{clcc}
\hline & Seat & $\begin{array}{c}\text { Seat } \\
\text { Mass } \\
(\mathrm{kg})\end{array}$ & $\begin{array}{c}\text { Peak Load } \\
\text { in Rear } \\
\text { Restraint } \\
(\text { KN })\end{array}$ \\
\hline 1 & Test Seat & 36 & 12.7 \\
2 & Wheelchair & 55 & 11.4 \\
3 & Wheelchair & 55 & 12.8 \\
4 & Test Seat & 36 & 13.1 \\
\hline
\end{tabular}

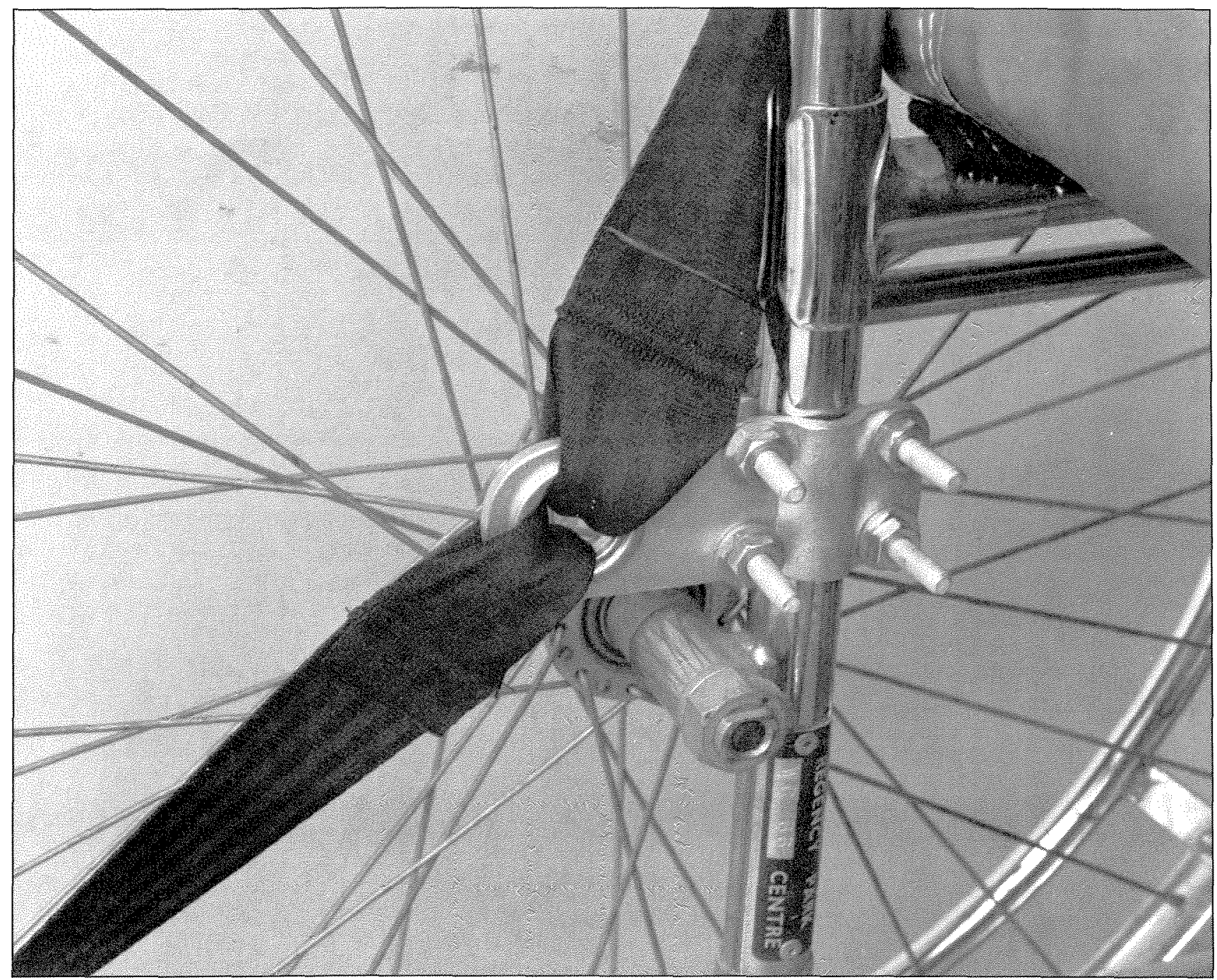

Figure 6b.

The steel bracket that unites the wheelchair frame, the lap belt, and the rear restraint. 


\section{Results}

Tests results are given in Table 3. A comparison of typical load/time records for the rear restraints (Figure 7) shows similar profiles for the Zimmer GB wheelchair of $55 \mathrm{~kg}$ and the test seat of $36 \mathrm{~kg}$.

We concluded that a rigidly constructed test seat of $36 \mathrm{~kg}$ generates similar loads of restraint to a typical powered wheelchair of $55 \mathrm{~kg}$. Although the wheelchair and the test seat had different masses, the similarity of restraint loads was explained by the dissipation of impact energy into the standard wheelchair due to frame and wheel deformation and stretching of the upholstery. High-speed film records of the dynamic trials revealed that the dynamic interactions between the dummy and seating were more violent with the rigid test seat than with the wheelchair. This is consistent with the more ragged restraint load profile exhibited with the test seat. (Figure 7)

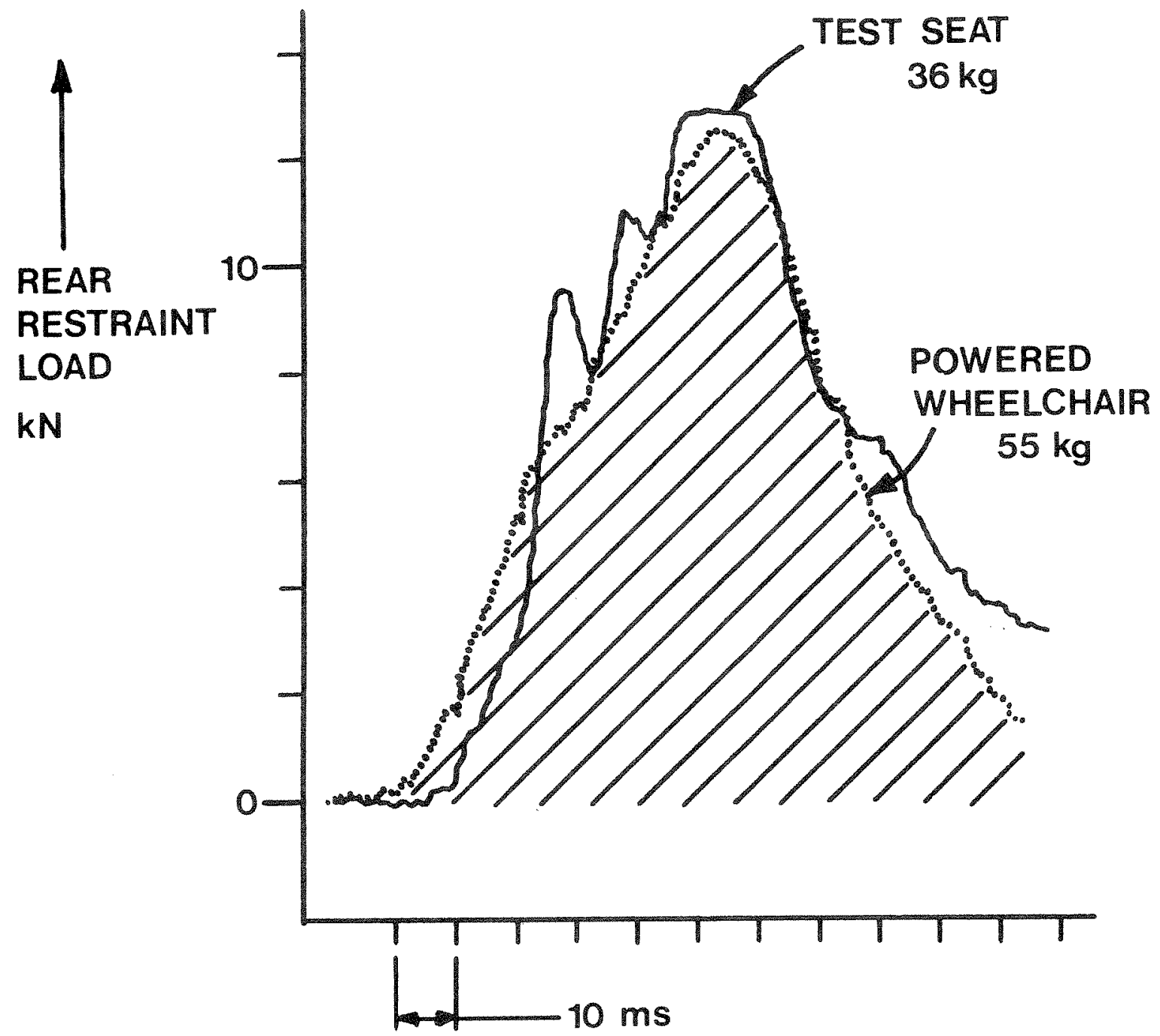

TIME

Figure 7.

Comparison of rear restraint loading traces during dynamic testing with two types of seating: a typical powered wheelchair seat and the Standard test seat. 


\section{REFERENCES}

1. Australian Design Rule $4 D$ for Seat Belts. Department of Transport, Commonwealth of Australia, 1984.

2. Code of Practice and Special Provisions for the Carriage of Passengers in Wheelchairs on Public Service Vehicles, Publication VSE 518. Vehicle Standards and Engineering Division, United Kingdom Department of Transport, 1982.

3. KALlieris D ET AL.: Behaviour and response of wheelchair, passenger and restraint systems used in buses during impact. Proceedings of the 25th Stapp Car Crash Conference, Society of Automotive Engineers, Inc., San Francisco, 613-647, 1981.

4. Motor Vehicles for the Transportation of Physically Disabled Persons, CAN 3-D409-M48. Canadian Standards Association, 1984.

5. PetTy SPF AND Chatfield AG: Static and Dynamic Tests of Wheelchair Restraints for Use in Public Service Vehicles, TRRL Laboratory Report 1087. United Kingdom Department of Transport, 1983.

6. Red E, Hale K, MCDermott M, Mooring B: Wheelchair restraint systems, dynamic test results and the development of standards. Proceedings of the 26th Stapp Car Crash Conference, Society of Automotive Engineers, Inc., San Francisco, 269-290, 1982.
7. Requirements for Adaptive Equipment Purchased for Handicapped Drivers. Department of Rehabilitation and Department of General Services, State of California, 1982.

8. SCHNeIDER LW: Dynamic Testing of Restraint Systems and Tie-downs for Use with Vehicle Occupants Seated in Powered Wheelchairs. University of Michigan Highway Safety Research Institute, 1981.

9. Schneider LW, Melvin JW, CoOney CE: Impact Sled Test Evaluation of Restraint Systems Used in Transportation of Handicapped Children, Technical Paper 790074. Society of Automotive Engineers, Inc., 1979.

10. SEeger BR: Crashworthy restraints for wheelchair occupants in motor vehicles. Tech Aid Disabled J 3(4):35$41,1983$.

11. Seeger BR And Caudrey DJ: Crashworthiness of restraints for physically disabled children in buses. Rehabil Lit 44(11-12):332-355, 1983.

12. SEeger BR AND LUXTON RE: A crashworthy restraint system for disabled people in wheelchairs in motor vehicles. Proceedings of the 2nd International Conference on Rehabilitation Engineering, Ottawa, 17-18, 1984.

13. WEVERS HW: Wheelchair and occupant restraint system for transportation of handicapped passengers. Arch Phys Med Rehabil 64:374-377, 1983. 